\title{
Treatment of acute suppurative cholecystitis with coagulopathy by percutaneous transhepatic gallbladder drainage after hepatic needle-track ablation: report of a new technique
}

\author{
Huai-Jie Cai ${ }^{\#}$, Wei Wang ${ }^{\sharp}$, Jian-Hua Fang^${ }^{\wedge}$, Chuang-Hua Chen^ , Fan-Lei Kong^, Chen-Ke Xu^ \\ Department of Ultrasound, Affiliated Hangzhou First People's Hospital, Zhejiang University School of Medicine, Hangzhou, China \\ "These authors contributed equally to this work. \\ Correspondence to: Jian-Hua Fang, MB, Chief Physician. Department of Ultrasound, Affiliated Hangzhou First People's Hospital, Zhejiang University \\ School of Medicine, No. 261, Huansha Road, Shangcheng District, Hangzhou 310006, Zhejiang Province, China. Email: fjh173@163.com.
}

Submitted Apr 16, 2020. Accepted for publication Oct 02, 2020.

doi: 10.21037/qims-20-576

View this article at: http://dx.doi.org/10.21037/qims-20-576

\section{Introduction}

Acute suppurative cholecystitis (ASC) is a common acute abdominal disorder in clinical practice, most often in older women, and the pathogenesis underlying $90 \%$ of cases is obstruction of the cystic duct by gallstones (1). The incidence of gallbladder calculi increases with age, and many patients with ASC will also have diseases of the circulatory and respiratory systems, diabetes, and poor kidney function. Moreover, a systemic infection caused by ASC can aggravate these complications, making it difficult to control the infection with conservative treatment only. However, emergency surgery in such patients with comorbidities may lead to a higher incidence of complications and mortality. In 1980, Radder first reported successful drainage of a gallbladder empyema accumulation by ultrasound-guided percutaneous cholecystostomy (2). Clinical studies have confirmed that percutaneous transhepatic gallbladder drainage (PTGD) is a safe and effective treatment for highrisk ASC (3). Gallbladder drainage and decompression can reduce the symptoms of poisoning and improve liver function and systemic condition, gaining time to manage severe medical diseases, allowing the patient to recover from a critical illness safely, and then undergoing laparoscopic cholecystectomy (LC) at a later date. However, PTGD can significantly increase the risk of surgical bleeding in critically ill patients with a coagulopathy. Anderloni et al. (4) reported using for the first time a recently developed lumenapposing, fully-covered, self-expanding metal stent mounted on an electrocautery-enhanced delivery system to perform emergency endoscopic ultrasound-guided gallbladder drainage (EUS-GBD) in 4 prohibitively high-risk surgical patients with ASC. The patients had a prolonged INR and/or were taking anticoagulants. Unfortunately, 2 of the treated patients died 2 and 3 days after the procedure due to multiorgan failure, but without any signs of bleeding. We report the successful management of a case of PTGD after hepatic needle-track ablation, which will expand the surgical indications for PTGD, avoid emergency surgery, and facilitate subsequent, non-urgent LC.

\section{Case presentation}

A 51-year-old woman was admitted to the hospital because of upper abdominal pain for 3 days and accompanying nausea and vomiting for 1 day. The patient had been diagnosed with hepatitis B, cirrhosis, and diabetes 5 months

\footnotetext{
^ ORCID: Huai-Jie Cai, 0000-0002-7012-5293; Wei Wang, 0000-0002-4485-6113; Jian-Hua Fang, 0000-0002-1333-4179; Chuang-Hua Chen, 0000-0003-1767-459X; Fan-Lei Kong, 0000-0001-6613-7251; Chen-Ke Xu, 0000-0003-2676-0430
} 
Table 1 Pre- and post-operative changes for PTGD

\begin{tabular}{lcc}
\hline $\begin{array}{l}\text { Laboratory } \\
\text { examinations }\end{array}$ & PTGD preoperative & $\begin{array}{c}\text { PTGD postoperative } \\
\text { (3 days) }\end{array}$ \\
\hline WBC $\left(\times 10^{9} / \mathrm{L}\right)$ & 9.6 & 5.7 \\
$\mathrm{NE}\left(\times 10^{9} / \mathrm{L}\right)$ & 8.9 & 4.8 \\
$\mathrm{Hb}(\mathrm{g} / \mathrm{L})$ & 103 & 117 \\
$\mathrm{PLT}\left(\times 10^{9} / \mathrm{L}\right)$ & 38 & 126 \\
$\mathrm{CRP}(\mathrm{mg} / \mathrm{L})$ & 206 & 15 \\
$\mathrm{PCT}(\mathrm{ng} / \mathrm{mL})$ & 9.0 & 1.2 \\
$\mathrm{PT}(\mathrm{s})$ & 17.4 & 13.9 \\
$\mathrm{INR}$ & 1.58 & 1.26 \\
$\mathrm{APTT}(\mathrm{s})$ & 34.4 & 25.1 \\
$\mathrm{FG}(\mathrm{g} / \mathrm{L})$ & 4.36 & 2.5 \\
\hline
\end{tabular}

APTT, activated partial thromboplastin time; CRP, C-reactive protein; FG, fibrinogen; $\mathrm{Hb}$, hemoglobin; INR, international normalized ratio; NE, neutrophils; PCT, procalcitonin; PLT, platelet count; PT, prothrombin time; PTGD, percutaneous transhepatic gallbladder drainage; WBC, white blood cell count.

previously.

The abdominal pain was persistent; there was no diarrhea or black stool and normal flatus and defecation. The physical examination findings were as follows: Murphy's sign, positive; temperature, $38.4{ }^{\circ} \mathrm{C}$; heart rate 78 beats/min; blood pressure, $87 / 62 \mathrm{mmHg}$; and $\mathrm{SpO}_{2}, 100 \%$. The laboratory findings were as follows: white blood cell count, $9.6 \times 10^{9} / \mathrm{L}$; neutrophil count, $8.9 \times 10^{9} / \mathrm{L}$; hemoglobin, $103 \mathrm{~g} / \mathrm{L}$; platelet count, $38 \times 10^{9} / \mathrm{L}$; C-reactive protein, $206 \mathrm{mg} / \mathrm{L}$; albumin, $24.7 \mathrm{~g} / \mathrm{L}$; glucose, $10.42 \mathrm{mmol} / \mathrm{L}$; K+, $3.55 \mathrm{mmol} / \mathrm{L}$; procalcitonin, $9.0 \mathrm{ng} / \mathrm{mL}$; prothrombin time activity, $17.4 \mathrm{~s}$; activated partial thromboplastin time, $34.4 \mathrm{~s}$; fibrinogen, $4.36 \mathrm{~g} / \mathrm{L}$; $\mathrm{pH}$ 7.34; carbon dioxide tension, $34.5 \mathrm{mmHg}$; bicarbonate level, $18.6 \mathrm{mmol} / \mathrm{L}$; base excess, $6.8 \mathrm{mmol} / \mathrm{L}$ (Table 1). Ultrasonography of the upper abdomen showed unevenly and decreased liver parenchyma echo with multiple hyperechoic nodules. The size of the gallbladder was $9.1 \times 3.1 \mathrm{~cm}$, with a thickened wall $(\approx 0.9 \mathrm{~cm})$ (Figure 1A). The bile in the gallbladder had poor sound penetration, and the neck of the gallbladder had a stone approximately $1.6 \mathrm{~cm}$ in size. Computed tomography of the upper abdomen showed multiple nodular shadows in the liver, an enlarged gallbladder with a thickened wall, a nodular high-density shadow in the gallbladder lumen and a small amount of inflammatory exudate around the gallbladder (Figure 1B). The diagnosis was the incarceration of gallstones causing ASC with septic shock.

\section{Treatment}

The patient received norepinephrine $(0.04 \mathrm{~g} / \mathrm{kg} / \mathrm{min})$ to maintain hemodynamics, meropenem $(1.0 \mathrm{gQ} 8 \mathrm{H})$ as an antibiotic, platelets $(20 \mathrm{U})$, vitamin $\mathrm{K}(130 \mathrm{mg} \mathrm{QD})$ to improve blood coagulation, magnesium isoglycyrrhizinate injection (200 $\mathrm{mg}$ QD) to protect the liver, and phloroglucinol (80 $\mathrm{mg}$ QD) and magnesium sulfate (5 $\mathrm{g}$ QD) as symptomatic treatment. After 5 days, symptoms had not improved, so hepatic needle ablation was first performed under general anesthesia, then PTGD was performed along the needle ablation track for the treatment of cholecystitis. The technique is described below in 5 steps (Figure 2).

In step 1 , contrast-enhanced ultrasonography (CEUS) was used to ensure there were no large vessels in the puncture path between the right lobe of the liver and the gallbladder (Video 1, Figure 2A). In step 2, under real-time ultrasonic monitoring, a Star RF fixed radiofrequency needle (antenna length, $2 \mathrm{~cm}$ ) was precisely directed to the target position, and standard radiofrequency treatment (time, $1 \mathrm{~min}$; power, $100 \mathrm{~W}$ ) was started. Subsequently, the echo around the needle was enhanced, the range gradually expanded, and the predetermined range was completely covered (Video 2). On completion of radiofrequency therapy, the water circulation system was closed, and the radiofrequency needle was heated to burn muscle, subcutaneous fat instantly, and skin, then quickly removed to prevent bleeding in the needle passage (Figure $2 B$ ). In step 3 , CEUS was used again to evaluate the channel between the right lobe of the liver and the gallbladder, which showed no contrast agent perfusion in this area (Video 3, Figure $2 C$ ). In step 4 , a $6 \mathrm{~F}$ pigtail catheter was slowly introduced along the path of the first needle puncture. When the needle tip reached the liver capsule, it was directed through the liver tissue that had been ablated, and then entered the gallbladder (Video 4). After the needle core was extracted, turbid liquid flowed out. After the needle sheath was removed, the thin guiding line was tightened and fixed, and the end of the drainage tube was bent into a pig's tail, and fixed so the pus inside the gallbladder could be aspirated (Figure $3 A$ ). In step 5, the location of the catheter was confirmed to be in the ideal location by intravenous angiography and cholangiography (PTGD tube) (Video 5, Figure 2D). No bleeding was observed at the site of puncture of the liver. 

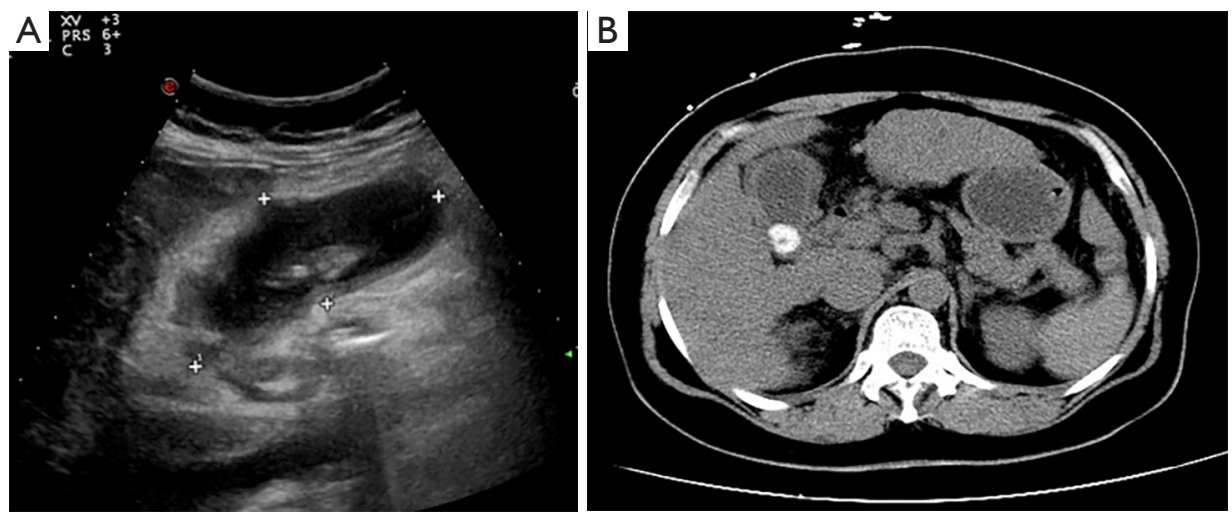

Figure 1 Imaging characteristics of acute suppurative cholecystitis in the patient. (A) Ultrasonic examination shows the gallstone, gallbladder enlargement, and thickening of the gallbladder wall. (B) Computed tomography showed the density shadow of the stone in the gallbladder lumen and a small amount of inflammatory exudate around the gallbladder.
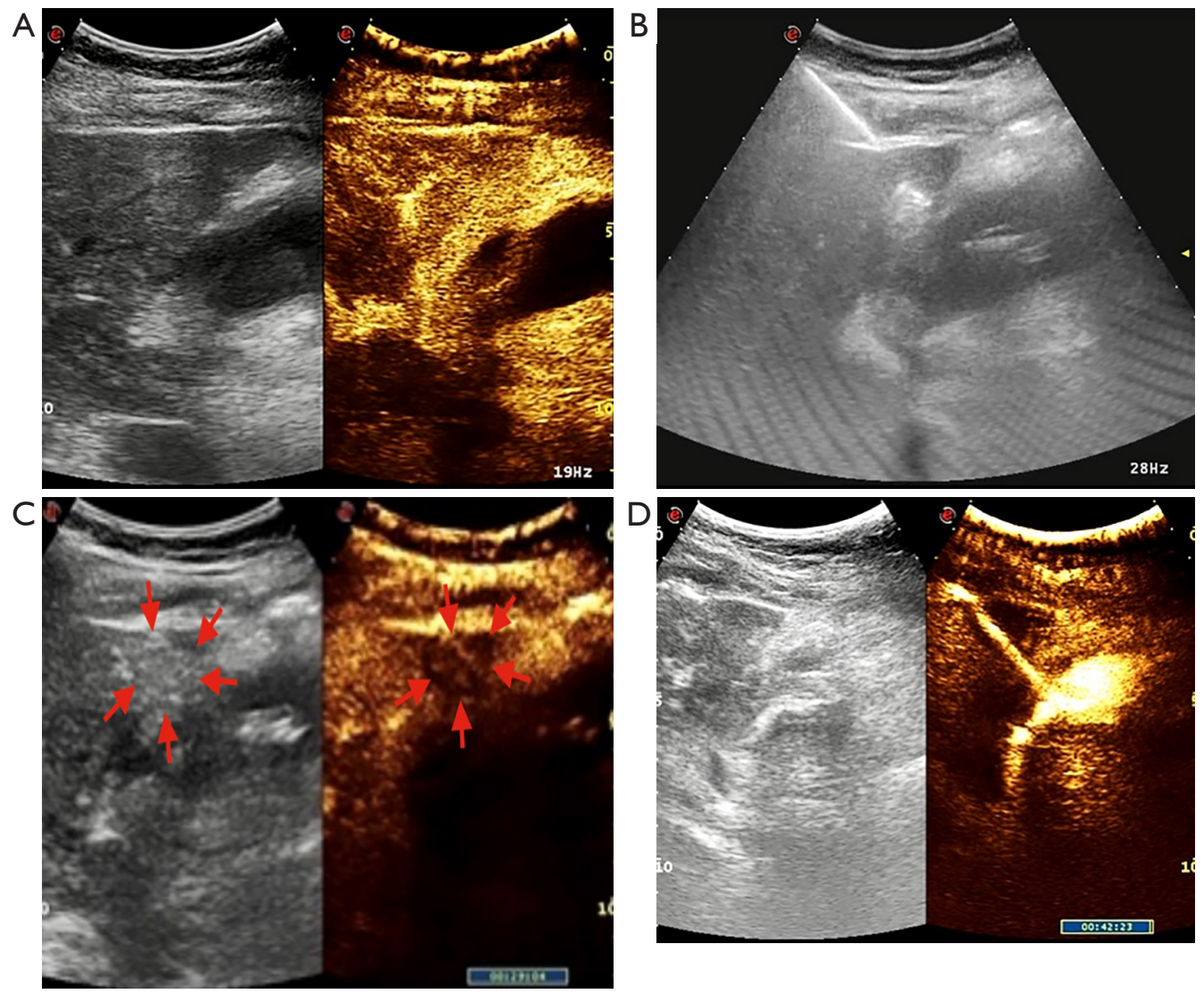

Figure 2 Preoperative comprehensive evaluation and operative technique. (A) Contrast-enhanced ultrasonography evaluates the safety of the puncture path. (B) The needle track of the liver is ablated. (C) No perfusion in the hepatic needle track by CEUS (arrows). (D) Venography and PTGD angiography confirm the puncture path is within the ablation range and the side hole of the drainage catheter is within the gallbladder lumen. CEUS, contrast-enhanced ultrasonography; PTGD, percutaneous transhepatic gallbladder drainage. 

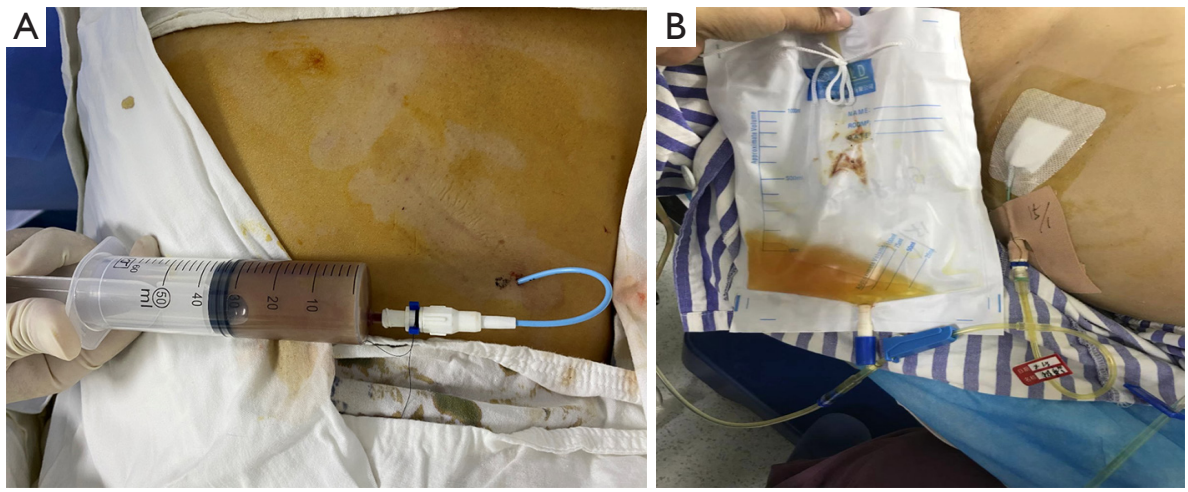

Figure 3 Drainage of fluid from the gallbladder. (A) Pus removed immediately after PTGD. (B) Serous liquid flowed from the drainage tube after 72 h. PTGD, percutaneous transhepatic gallbladder drainage.

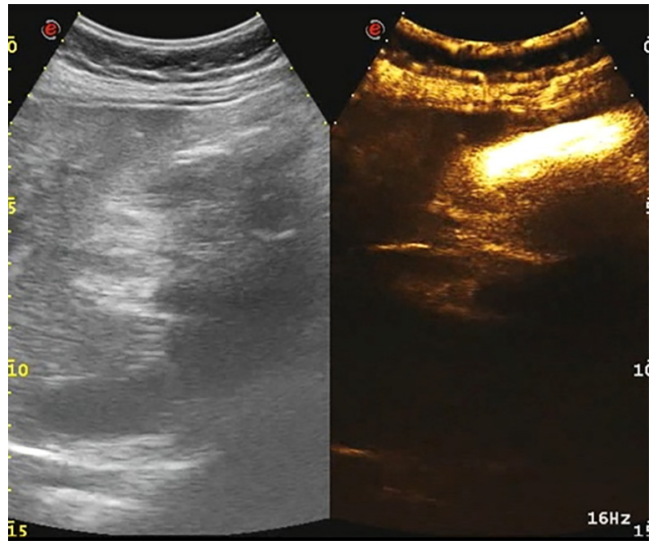

Figure 4 Due to the trouble of clear fluid draining and ascites simultaneously, cholangiography (PTGD tube) was performed again to ensure that the tube was in the gallbladder, so that it could be confirmed that the drainage was serous but not ascites. PTGD, percutaneous transhepatic gallbladder drainage. PTGD, percutaneous transhepatic gallbladder drainage.

\section{Outcome and follow-up}

On the first day after PTDG, the patient's pain was immediately relieved, and the inflammatory indicators normalized 3 days later (Table 1). Because the stones were incarcerated in the neck of the gallbladder, the fluid from the drainage tube was white (Figure 3B). Cholangiography (PTGD tube) was performed again to confirm the location of the tube to eliminate the possibility that the tube would fall off and lead to the outflow of ascites (Figure 4). Five days after PTGD, the patient requested to be discharged from the hospital for recuperation and undergo LC at another time.

\section{Discussion}

ASC is one of the most common acute abdominal disorders affecting older women. When combined with the measurement of C-reactive protein, it is relatively easy to diagnose from imaging findings and clinical symptoms (5). However, the mortality and complication rates after ASC surgery in the elderly are relatively high. Using ultrasound as a non-invasive and inexpensive tool has been recently applied to PTGD because it is not only highly specific for biliary obstruction and gallstones, but can also identify the hepatic artery, portal vein, and bile duct (6-8). Cholangiography with PTGD can visualize the anatomic structure of the biliary tract and the location of incarcerated gallstones, thus providing important information for subsequent surgical treatment and avoiding intra-operative bile duct injury. Currently, the treatment of critically ill patients with ASC is more likely to be pre-emptive PTGD to relieve acute infection, and LC performed 6 weeks later. The major advantages of this combination of procedures include less trauma, faster recovery, greater safety, fewer complications, and a significantly lower conversion rate to open surgery $(9,10)$. However, elderly patients have comorbidities, and when combined with extensive adhesions involving the gallbladder, are negative factors for LC. PTGD also has complications, such as catheter occlusion, peritonitis due to bile leakage, and bleeding $(11,12)$, but these complications are related to the timing of the PTGD. For patients with acute and severe disease, prompt intervention can improve the success rate of PTGD and reduce the incidence of complications (13).

In general, elderly patients with heart, brain, lung, and other common diseases cannot tolerate surgery. Pyogenic 
cholecyst, the poor effect of drug treatment, course of the disease $>48-72 \mathrm{~h}$, the diameter of the gallbladder $>8 \mathrm{~cm}$, and the wall of the gallbladder thicker than $4 \mathrm{~mm}$ are indications for prompt PTGD. Patients with abnormal coagulation and severe bleeding tendency, patients with a large number of ascites and a free gallbladder, patients with an inappropriate gallbladder puncture path, and patients highly suspected to gallbladder perforation, PTGD should be reconsidered by clinicians.

Given that the present patient had a coagulopathy and a severe bleeding tendency, PTGD was not the preferred initial treatment; however, after 5 days of symptomatic treatment, including antibiotics and fluid rehydration, neither the infection nor the coagulopathy was alleviated. Through a multidisciplinary team, five strategies were proposed: (I) continue with the original treatment regimen; (II) LC; (III) LC by laparotomy; (IV) EUS-GBD; or (V) PTGD after needle-track ablation, then LC at a selected time after recovery. There were risks associated with all strategies: the patient's poor response to medication; the high risk of LC or laparoscopic cholecystectomy; the anatomic relationship between the gallbladder, the duodenum, or gastric wall, which are not adjacent to each other, can make EUS-GBD more difficult; and displacement between the puncture point and the gallbladder. However, after a discussion with family members, the patient chose our innovative PTGD technique.

Relevant considerations are as follows: (I) the liver needle ablation time is different from the time needed for the ablation of liver cancer, which can be up to $10 \mathrm{~min}$ to ensure the cancer cells are killed, whereas the time for needle ablation is only $1 \mathrm{~min}$. The extent of tissue solidification conforming to the predicted area is identified by intravenous contrast-enhanced ultrasound. (II) It is essential to ensure that the side hole of the drainage catheter is completely within the gallbladder cavity, which not only prevents the catheter from dislodging but also prevents bile leakage. Therefore, intracavitary angiography should be performed for postoperative confirmation. (III) General anesthesia is required for the procedure because the patient will be unable to cooperate due to pain during the puncture, which will seriously affect the accuracy of the puncture and even cause serious complications. (IV) Symptomatic medical treatment is significant.

PTGD after hepatic needle-track ablation is a beneficial preventative treatment. It can effectively reduce the risk of surgery. This is only a case report, so we are still conducting more experiments to verify the feasibility of this technology.

\section{Conclusions}

For elderly and high-risk ASC patients, PTGD is preferred to reduce biliary pressure, effectively relieve symptoms, avoid the risks of surgery, reduce mortality, and provide the "golden surgical time" for elective gallbladder excision. Hepatic needle-track ablation may be an effective way to reduce the surgical bleeding risk in those with a coagulopathy.

\section{Acknowledgments}

Funding: None.

\section{Footnote}

Conflicts of Interest: All authors have completed the ICMJE uniform disclosure form (available at http://dx.doi. org/10.21037/qims-20-576). The authors have no conflicts of interest to declare.

Informed Consent: Consent was obtained from the patient for publication of this report and any accompanying images.

Open Access Statement: This is an Open Access article distributed in accordance with the Creative Commons Attribution-NonCommercial-NoDerivs 4.0 International License (CC BY-NC-ND 4.0), which permits the noncommercial replication and distribution of the article with the strict proviso that no changes or edits are made and the original work is properly cited (including links to both the formal publication through the relevant DOI and the license). See: https://creativecommons.org/licenses/by-nc-nd/4.0/.

\section{References}

1. Rogers PN. Long-term outcome of patients with acute cholecystitis receiving antibiotic treatment: a retrospective cohort study. World J Surg 2014;38:355-6.

2. Radder RW. Ultrasonically guided percutaneous catheter drainage for gallbladder empyema. Diagn Imaging 1980;49:330-3.

3. Jia B, Liu K, Tan L, Jin Z, Liu Y. Percutaneous Transhepatic Gallbladder Drainage Combined with Laparoscopic Cholecystectomy versus Emergency Laparoscopic Cholecystectomy in Acute Complicated Cholecystitis: Comparison of Curative Efficacy. Am Surg 2018;84:438-42. 
4. Anderloni A, Attili F, Sferrazza A, Rimbaș M, Costamagna G, Repici A, Larghi A. EUS-guided gallbladder drainage using a lumen-apposing self-expandable metal stent in patients with coagulopathy or anticoagulation therapy: a case series. Endosc Int Open 2017;5:E1100-3.

5. Beliaev AM, Marshall RJ, Booth M. C-reactive protein has a better discriminative power than white cell count in the diagnosis of acute cholecystitis. J Surg Res 2015;198:66-72.

6. Xu EJ, Zheng RQ, Su ZZ, Li K, Ren J, Guo HY. Intrabiliary contrast-enhanced ultrasound for evaluating biliary obstruction during percutaneous transhepatic biliary drainage: a preliminary study. Eur J Radiol 2012;81:3846-50.

7. Wagner A, Mayr C, Kiesslich T, Berr F, Friesenbichler P, Wolkersdorfer GW. Reduced complication rates of percutaneous transhepatic biliary drainage with ultrasound guidance. J Clin Ultrasound 2017;45:400-7.

8. Cokkinos DD, Antypa EG, Tsolaki S, Skylakaki M, Skoura A, Mellou V, Kalogeropoulos I. Contrast-enhanced ultrasound examination of the gallbladder and bile ducts: A pictorial essay. J Clin Ultrasound 2018;46:48-61.

9. Hu YR, Pan JH, Tong XC, Li KQ, Chen SR, Huang

Cite this article as: Cai HJ, Wang W, Fang JH, Chen CH, Kong FL, Xu CK. Treatment of acute suppurative cholecystitis with coagulopathy by percutaneous transhepatic gallbladder drainage after hepatic needle-track ablation: report of a new technique. Quant Imaging Med Surg 2021;11(4):1674-1679. doi: 10.21037/qims-20-576
Y. Efficacy and safety of B-mode ultrasound-guided percutaneous transhepatic gallbladder drainage combined with laparoscopic cholecystectomy for acute cholecystitis in elderly and high-risk patients. BMC Gastroenterol 2015;15:81.

10. Peters R, Kolderman S, Peters B, Simoens M, Braak S. Percutaneous cholecystostomy: single centre experience in 111 patients with an acute cholecystitis. JBR-BTR 2014;97:197-201.

11. Inoue K, Ueno T, Douchi D, Shima K, Goto S, Takahashi M, Morikawa T, Naitoh T, Shibata C, Naito H. Risk factors for difficulty of laparoscopic cholecystectomy in grade II acute cholecystitis according to the Tokyo guidelines 2013. BMC Surg 2017;17:114.

12. Kothaj P, Okapec S, Kudelova A. Complications after percutaneous transhepatic drainage of the biliary tract. Rozhl Chir 2014;93:247-54.

13. Lucatelli P, Corradini SG, Corona M, Corradini LG, Cirelli C, Saba L, Poli E, Fanelli F, Wang H, Bezzi M Catalano C. Risk Factors for Immediate and DelayedOnset Fever After Percutaneous Transhepatic Biliary Drainage. Cardiovasc Intervent Radiol 2016;39:746-55. 